Europe's Journal of Psychology 1/2010, pp. 82-101

www.ejop.org

\title{
Zinc levels, cognitive and personality features in children with different socioeconomic backgrounds
}

\section{Victoria Papadopol}

Senior researcher

Department of Food Hygiene and Nutrition, Institute of Public Health, Iasi, Romania

\section{Eugenia Tuchendria}

Senior researcher

Department of Food Hygiene and Nutrition, Institute of Public Health, Iasi, Romania

\section{Iliana Palamaru}

Senior researcher

Department of Food Hygiene and Nutrition, Institute of Public Health, Iasi, Romania

\section{Abstract}

Zinc is an essential nutrient having a complex biological role, including neuropsychological aspects. The study aimed to compare zinc level and psychic features in two pupils groups from different socioeconomic backgrounds. It also ascertains the relationship between zinc levels and aspects of intellectual development (attention, memory, intelligence) and personality features (psychoticism, neuroticism and extraversion). 103 pupils from an orphanage and 100 pupils from a regular state school were investigated. They were 11-15 years old and apparently healthy. Serum and erythrocyte zinc mean values were higher in the regular state school group $(p=0.001$ in both cases). The distribution of subjects regarding intellectual development was different in the two groups ( $p=0.000$ in all cases) and personality features differed regarding psychoticism and neuroticism tendencies ( $p=0.019$ and $p=0.012$ respectively). The U-test showed a significant difference between the subjects with deficient serum zinc and those with normal serum zinc as regarding attention $(p=0.024)$ and intelligence $(p=0.035)$ and between the subjects with deficient erythrocyte zinc and those with normal erythrocyte zinc as regards extraversion $(p=0.011)$ in the group from the orphanage. Subjects with normal zinc status obtained higher (better) scores for psychological traits in 
all these situations. In conclusion, zinc levels and psychological features were different in the two groups of pupils. Our study pointed out a positive connection between zinc level and some aspects of intellectual developmental and personality features, emphasizing the importance of this trace element for the normal psychological status of children.

Key words: zinc, intellectual development, personality features, children (11-15 years), different socioeconomic conditions

\section{Background}

Literature (Connolly \& Kvalsvig, 1993; Pollitt, 1994) points to the negative effects of malnutrition on cognitive performances and generally on mental health. Malnutrition involves protein-energy ingestion but also micronutrients such as vitamins and minerals including zinc (Zn). Zn is an essential nutrient whose deficiency continues to be a modern health concern in both developing and developed countries (Sandstead \& Penland, 1997). The main cause of human Zn deficiency is consumption of diets containing little highly bioavailable Zn. Meat foods, especially red meat, are the best dietary sources of bioavailable $\mathrm{Zn}$, while foods rich in phytate and dietary fiber inhibit Zn retention.

Major adverse effects of Zn deficiency include, besides others, impaired neuropsychological functions among children and adults. This is because it contributes to the structure and function of the brain (Black, 1998). Zn is one of the most prevalent essential elements found in the brain. It is primarily retained in the hippocampus and its levels in this area are greater than those of any other element (Rajan et al, 1976). Structural studies have shown truncated dendritic arbors and reduced regional brain mass in the cerebellum, limbic system, and cerebral cortex in Zn deficiency. Neuronally, presinaptic boutons are dependent on adequate Zn for delivery of neurotransmitters to the synaptic cleft (Frederickson \& Danscher, 1990). It is important for the fetal brain development (Wauben et al., 1999) but it also has a number of roles in the functioning of the postnatal developing, and developed brain (Arnold \& Di Silvestro, 2005). It is also necessary for many homeostatic processes in the brain. Zn has the potential to act as a modulator of both excitatory and inhibitory neurotransmission (Smart, 2004; Kay \& Toth, 2008). Zn is also necessary for the production and modulation of melatonin, which helps regulate dopamine function (Sandyk, 1990; Chen et al., 1999) which is widely believed to be a key factor in attention deficit/hyperactivity disorder. Growing evidence suggests that Zn may also be a key mediator and modulator of the neuronal death associated with transient global ischemia and sustained seizures, as well perhaps as other neurological 
diseases states (Choi \& Koh, 1998). The studies of Wang \& al. (2001) suggest that Zn deficiency suppresses development of neural stem cells and this effect may lead to neuroanatomical and behavioral abnormalities in adults.

Postnatal moderate Zn deficiency in rats has demonstrated a number of brain effects, including impaired learned behavior and impaired cell maturation (Takeda, 2000; Yeiser et al., 2002). In humans, Zn deficiency has been proposed to lead to mental disturbances, loss of sensory acuity and impaired cognitive and psychological function (Levy \& Bray, 2009). Other authors noted irritability, emotional imbalance, sleeping disorders, mental lethargy (Neve \& Peretz, 1988), depression (McLoughlin \& Hodge, 1990). Arora \& al. (1987) found in mentally subnormal children values of serum Zn significantly lower than in controls. Walravens \& al. (1978) reported behavioral abnormalities in severe Zn deficiency. Prasad (1991) included mental disturbances among the clinical manifestations of severe $\mathrm{Zn}$ deficiency and mental lethargy among the manifestations of moderate $\mathrm{Zn}$ deficiency in human subjects. Severe Zn deficiency impairs thought process (Henkin, 1975). Less severe deficiency has more subtle effects on neuropsychological functions that are not perceived by affected individuals. Zn deficiency may affect cognitive development, though the mechanisms remain unclear (Bhatnagar \& Taneja, 2001). So, the role of $\mathrm{Zn}$ in this respect is not fully understood and its relationship with children's cognitive performance and personality features has been insufficiently studied.

For the purposes of this study, cognitive performance comprises known aspects of intellectual development (attention, memory, intelligence) and personality features are those included in the P-E-N model of Eysenck: psychoticism, extraversion, neuroticism.

Psychoticism can be defined as a predisposition or susceptibility towards psychotic behavior. It comprises of: behavioral disturbances, schizotypal disorders, antiauthoritative attitude, and non-acceptance of cultural norms but a high level of creativity. In children it means: isolation, lack of sensibility, aggression, lack of feelings of guilt and fear. The cognitive and emotional functions are not disturbed.

Neuroticism is an enduring tendency to experience negative emotional states such as: hyper-emotivity, hyper-excitability, anxiety, anger, impulsivity. Neuroticism can play a critical role in the development of depressive disorders (Hodgins \& Ellenbogen, 2003). It is sometimes called an emotional instability. Neuroticism is not in itself pathological but has tendencies that can become pathological in certain conditions (physical- related to living or working place or emotional conditions). 
Extraversion is a personality feature that manifests as positive mood and includes: sociability, enthusiasm and energy but also impulsivity. Extraverts enjoy being with people and also like to talk and draw attention to themselves.

The aims of the study were to compare Zn levels and psychological traits in two groups of children from different socio-economic backgrounds and to ascertain the relationship between the $\mathrm{Zn}$ levels and aspects of intellectual development and personality features in these children and teenagers.

It was hypothesized that socio-economic level influences the body zinc level which, in its turn, may influence intellectual development and the personality.

\section{Method}

\section{Subjects}

103 children from an orphanage (group I) made up of 71 girls and 32 boys and 100 children from a regular state school (group II) made up of 56 girls and 44 boys were investigated. They were 11 to 15 years old and apparently healthy (they had no diarrhea or other disorder). Their health status was appreciated through direct observation, consulting their register cards and talking to the nurse of the school. A questionnaire was filled in for every child.

Zinc determination

Blood was drawn from the antecubital vein of each subject. Serum and erythrocyte Zn were determined by atomic absorption spectrophotometry in air-acetylene flame (Roth \& Kirchgesner, 1980 and Prasad, 1985, respectively). The subjects were divided into normal and Zn-deficient ones depending on the low normal limits (normal ranges: serum Zn 70 - $120 \mu \mathrm{g} / \mathrm{dl}$ (Bogden \& al., 1987) and erythrocyte Zn 10 - 14 $\mu \mathrm{g} / \mathrm{ml}$ (Robson \& Spell, 1981).

\section{Diet investigation}

In orphanage, Zn content from all the meals sampled 7 consecutive days was determined (by atomic absorption spectrophotometry) after wet mineralization (STAS 10542/1-86). Also, the children were asked what they do not eat from the ordinary menu and what they eat beside it. 
In regular state school, weekly frequency consumption of some foods (meat, organs, eggs, dairy produces, and sweets) was recorded.

Psychological tests

The psychological examination was carried out with the help of specific tests. Two categories of tests were used: for cognitive capacity and for personality aspects. Thus, the cognitive capacity was investigated by:

- Attention using the Bourdon Amfimov test for capacity concentration (Martin, 2010)

The subject must, in a fixed interval, detect certain letter groups which are randomly disposed in lines on an A4 sheet. Data processing of the test is made quantitatively by framing into a classification and qualitatively by pointing out, besides the attention capacity concentration, aspects of visual perception, spatial orientation, disturbing factors, resistance to intellectual effort and monotonous activity. These psychological characteristics are corroborated with working speed (with implication of manual dexterity).

- Memory using the Rey verbal memory test (Vlaicu, 2000)

The psychologist reads slowly many words and the subjects have to keep in mind and reproduce in writing as much words as they can. The processing of the test answers is made quantitatively (global volume of the immediate correct reproduction) by reporting to a classification and qualitatively by pointing out the contiguity relationships of the stimulus word with other familiar words from the environment or from daily preoccupations. Also, the test gives information about the capacity of attention concentration and manual dexterity.

- Intelligence by the Raven test, standard variant (a non verbal intelligence test, non influenced by the educational activity) ( Raven \& al, 2003).

The task of the subject is to discover the relationships between the components of a matrix with geometrical figures. The time is not limited. The processing of the answers allows the calculation of the intelligence quotient, but also appreciates the capacity of visual, spatial perception, capacities of synthesis and analysis, comparison, learning, attention concentration and distributivity.

For attention, memory and intelligence a 5 step scale was used. It ranged from very weak = step 1 to very good = step 5 . 
The personality aspects (psychoticism, neuroticism and extraversion) were investigated using the Eysenck test (children variant, standardized for Romania) (Eysenck \& Eysenck, 1975; Şerbănescu-Grigoroiu, 1986). This test uncovers the socioemotional state of the personality. It comprises a number of questions regarding the reactions and behaviors of the investigated person in certain situations. The processing of the answers allows the framing of the results in certain levels according to the intensity of reactions and behaviors concerning psychoticism, neuroticism and extraversion. For the personality test, the subjects obtained scores from 1 to 3 (pathological to normal). This test was applied to 84 subjects in group I and 69 subjects in group II.

All these tests were chosen because they correspond to the aim of the paper; we have taken into account the effects of $\mathrm{Zn}$ deficit and what these tests qualitatively and quantitatively point out on the whole. The benefits of using these tests were:

- they have parallel forms that allow successive testing,

- they are standardized for Romania,

- $\quad$ they are easy to apply and it's possible to make a collective testing.

Statistical analysis

Statistical processing was performed by EPI INFO programme. Mean and standard deviations of the means were calculated. The next tests were used:

- Student "t" test to compare the mean Zn values in the two groups,

- "chi-square" test to investigate the association between Zn level and food frequency consumption, to compare the deficit frequencies and the distribution of the subjects (psychological tests),

- Mann-Whitney U-test to show the differences between the $\mathrm{Zn}$ level and psychological features.

The relationship between the $\mathrm{Zn}$ levels and the scores of psychological features was verified by Pearson correlation index (r). Statistical significance was set up at $p<0.05$.

Results

Table 1 presents the means +/- standard deviations values of $\mathrm{Zn}$ levels in the two groups of pupils. Both serum and erythrocyte Zn levels were higher in group II (regular state school). 
Table 1: Zinc mean values

\begin{tabular}{lcccc}
\hline & Group I & Group II & t-test & p \\
\hline Serum zinc $(\mu \mathrm{g} / \mathrm{dll})^{*}$ & $73.0+/-11.2$ & $82.3+/-17.4$ & 4.43 & 0.001 \\
Erythrocyte zinc $(\mu \mathrm{g} / \mathrm{ml})^{*}$ & $11.0+/-1.7$ & $11.7+/-1.3$ & 3.74 & 0.001 \\
\hline
\end{tabular}

${ }^{*}$ Mean +/- standard deviation; p: significance level

Agreeing with the upper values, serum and erythrocyte $\mathrm{Zn}$ deficit frequencies were higher in group I (Table 2) but the difference between the two groups was significant only for erythrocyte $\mathrm{Zn}$. As one can see, the majority of deficits were marginal.

Table 2: Zinc deficit frequencies

\begin{tabular}{|c|c|c|c|c|c|}
\hline & Zinc level & Group I (\%) & Group II (\%) & $\chi^{2}$ & $\mathrm{P}$ \\
\hline \multirow[t]{2}{*}{ Serum zinc } & $<70 \mu \mathrm{g} / \mathrm{dl}$ & 37.6 & 26.8 & 2.65 & 0.103 \\
\hline & $<70$ and $>62 \mu \mathrm{g} / \mathrm{dl}$ & 24.7 & 14.4 & & \\
\hline \multirow[t]{2}{*}{ Erythrocyte zinc } & $<10 \mu \mathrm{g} / \mathrm{ml}$ & 25.2 & 9.3 & 8.82 & 0.003 \\
\hline & $<10$ and $>8.9 \mu \mathrm{g} / \mathrm{ml}$ & 14.5 & 5.2 & & \\
\hline
\end{tabular}

p: significance level

Distribution by sexes showed a significant difference only in group I for serum Zn, the boys being advantaged (Table 3).

Table 3: Mean zinc values by sexes

\begin{tabular}{ccccc}
\hline & Girls & Boys & $\dagger$ & P \\
Serum zinc & $71.4+/-10.8$ & $76.7+/-11.3$ & 2.24 & 0.025 \\
Erythrocyte zinc & $11.1+/-1.8$ & $10.8+/-1.4$ & 0.92 & 0.638 \\
& \multicolumn{2}{c}{ Group II } \\
Serum zinc & $79.6+/-16.8$ & $85.6+/-17.7$ & 1.69 & 0.089 \\
Erythrocyte zinc & $11.6+/-1.4$ & $11.9+/-1.3$ & 0.84 & 0.591 \\
\hline
\end{tabular}

Further, the groups were not divided by sexes in order to obtain a better statistical significance for the applied testes. 
Analysis of the weekly menus from the orphanage emphasized a mean Zn content of $9.05 \pm 2.65 \mathrm{mg} \mathrm{Zn} /$ day (range: $6.37-13.25 \mathrm{mg} /$ day). The frequency of food consumption in the week was as follows: meat - 3 times, organs - once, dairy produces -3 times, eggs - twice, sweets -3 times. Probation of the food preferences of the children showed that some of them did not eat vegetable hotchpotch, bacon, green beans, which have, otherwise, a low Zn content, but some of them declared that they do not eat meat (especially beef meat) and eggs. $99 \%$ of children had the habit to eat bread, and most of them to eat many sweets beside the meals from the orphanage eating hall.

Investigation of the eating habits of the children from regular state school, showed that $60.6 \%$ of children eat meat 2-3 times by a week and $26.3 \%$ more, and $50.5 \%$ of children eat eggs 2-3 times by a week and $38.4 \%$ more (Table 4 ).

Table 4: Weekly frequencies of food consumption in regular state school (\%)

\begin{tabular}{ccccc}
\hline & $\begin{array}{c}\text { No } \\
\text { consume }\end{array}$ & Once & $2-3$ times & $>=4$ times \\
\hline Meat & 0 & 13.1 & 60.6 & 26.3 \\
Organs & 21.2 & 68.7 & 9.1 & 1.0 \\
Eggs & 0 & 11.1 & 50.5 & 38.4 \\
Dairy produces & 0 & 11.1 & 47.5 & 41.4 \\
Sweets & 0 & 9.1 & 29.3 & 61.6 \\
\hline
\end{tabular}

Serum or erythrocyte Zn level did not associate with frequency of food consumption ( $p>0.05$ for "chi square" in any case). $83.8 \%$ of the children eat bread besides meals.

The distribution of the subjects as regard to the intellectual development was significantly different in group I versus group II (Figure 1). 
Figure 1: Comparison of intellectual development

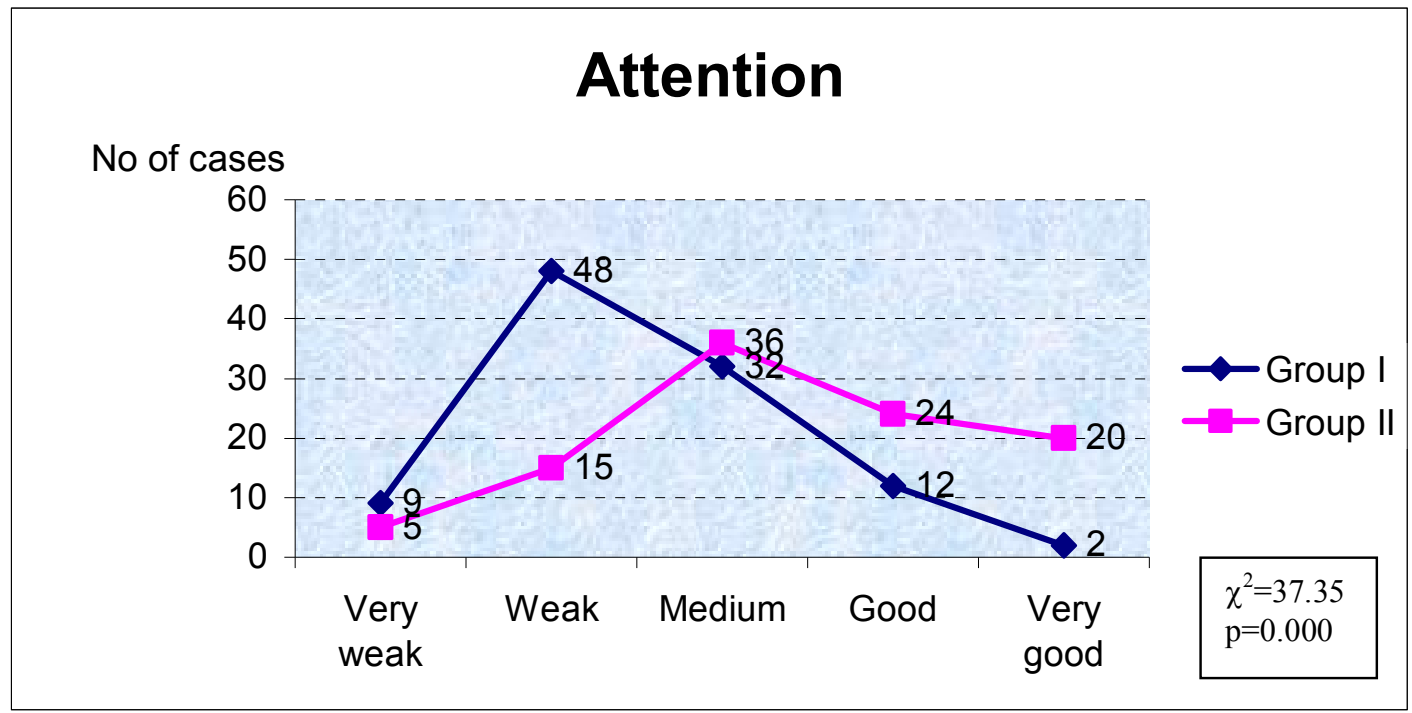

\section{No of cases \\ Memory}

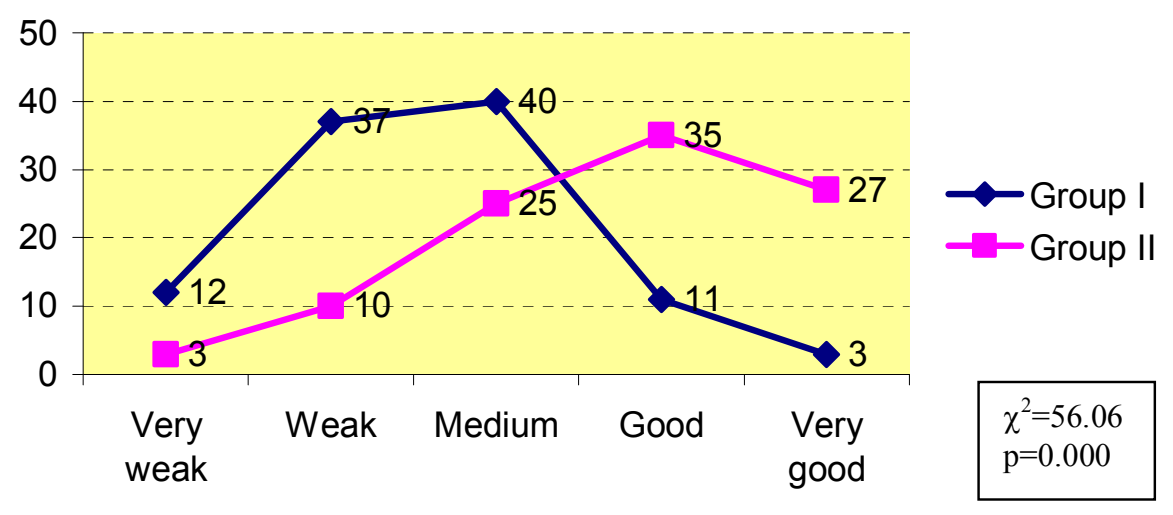

No of cases

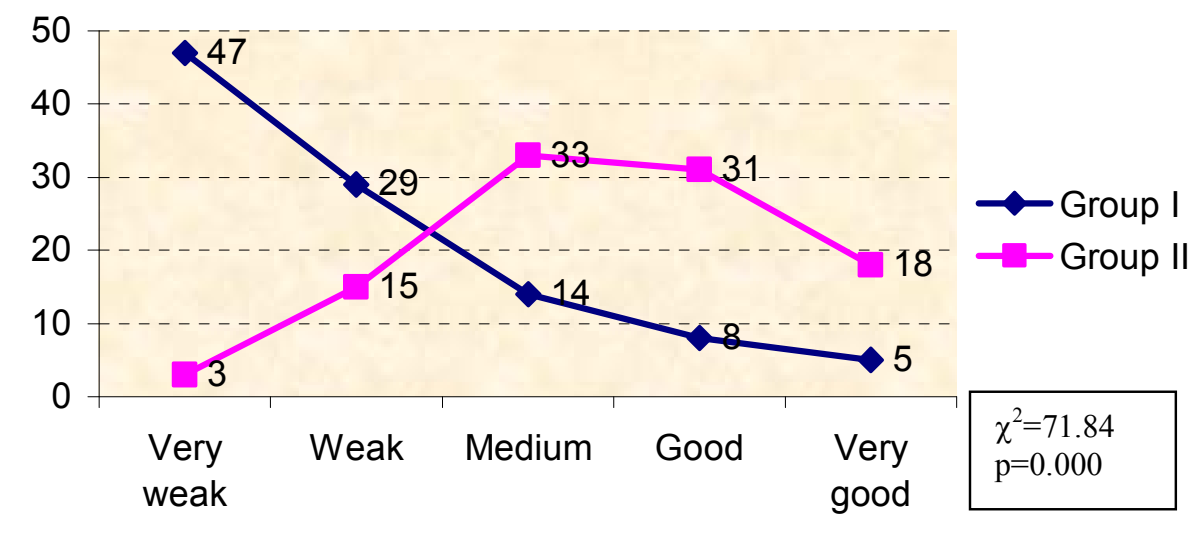


Also, the personality features in the two groups differed significantly regarding psychoticism and neuroticism tendencies (Figure 2).

Figure 2. Comparison of personality features
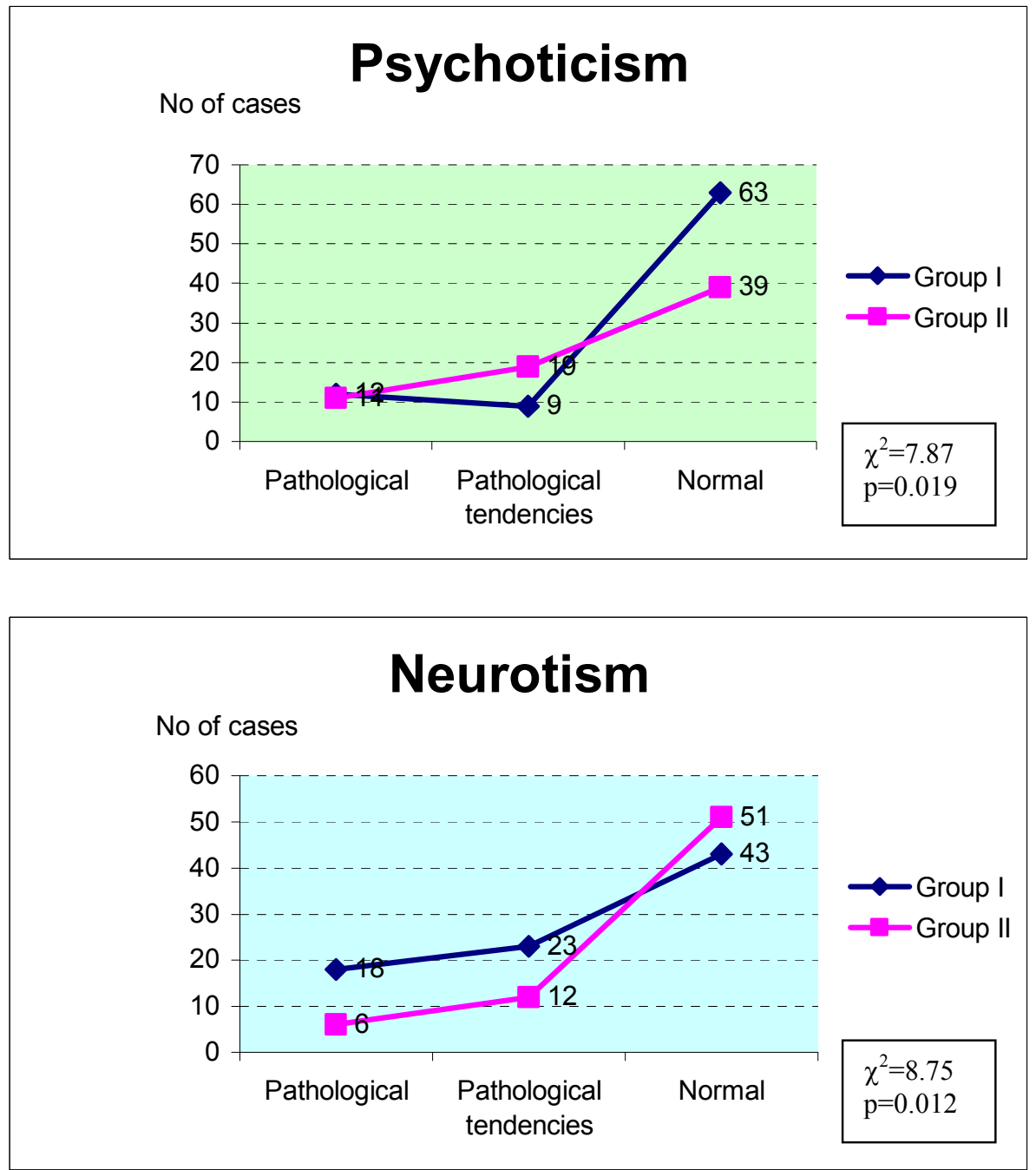

\section{Extraversion}

No of cases

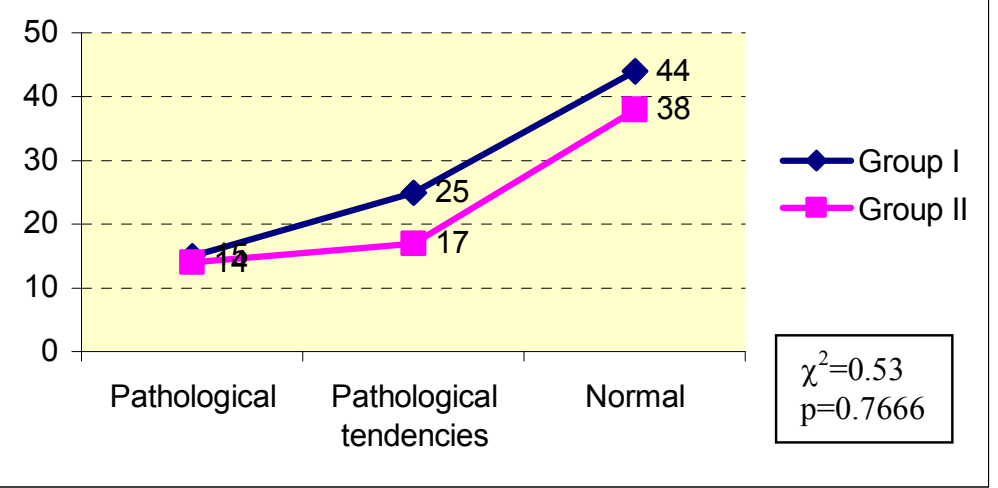


The U-test showed in group I a significant difference between the subjects with normal serum $\mathrm{Zn}$ and those with deficient serum $\mathrm{Zn}$ regarding attention and intelligence, and between the subjects with normal erythrocyte $\mathrm{Zn}$ and those with deficient erythrocyte Zn regarding extraversion (Table 5).

Table 5: Relationships (associations) between zinc deficit and psychic features

\begin{tabular}{|c|c|c|c|c|c|c|}
\hline & Group & Subjects & $\begin{array}{c}\text { No of } \\
\text { subjects }\end{array}$ & Mean +/- SD* & U-test & $p$ \\
\hline Serum Zn - & I & Zn deficient & 38 & $2.29+/-0.87$ & 5.06 & 0.024 \\
\hline Attention & & Zn normal & 63 & $2.67+/-0.88$ & & \\
\hline Serum Zn - & I & Zn deficient & 38 & $1.74+/-1.13$ & 4.43 & 0.035 \\
\hline Intelligence & & Zn normal & 63 & $2.16+/-1.18$ & & \\
\hline Erythrocyte Zn - & I & Zn deficient & 20 & $2.00+/-0.72$ & 6.33 & 0.011 \\
\hline Extraversion & & Zn normal & 64 & $2.45+/-0.75$ & & \\
\hline Erythrocyte Zn - & I & Zn deficient & 20 & $3.00+/-1.22$ & 3.48 & 0.061 \\
\hline Neuroticism & & Zn normal & 64 & $3.78+/-1.02$ & & \\
\hline Erythrocyte Zn - & $\|$ & Zn deficient & 9 & $3.00+/-1.22$ & 3.67 & 0.055 \\
\hline Memory & & Zn normal & 88 & $3.77+/-1.02$ & & \\
\hline
\end{tabular}

*Mean +/- standard deviation for the psychic features scores;

$\mathrm{p}$ : significance level

There was also a less significant difference between the subjects with normal erythrocyte $\mathrm{Zn}$ and those with deficient erythrocyte $\mathrm{Zn}$ regarding neuroticism in group I $(p=0.061)$ and regarding memory in group II $(p=0.055)$.

Erythrocyte $\mathrm{Zn}$ positively correlated with extraversion in group I and with memory in group II (Table 6).

Table 6. Correlations of zinc levels and psychic features

\begin{tabular}{ccccc}
\hline & Group & $r$ & $n$ & $p$ \\
\hline Erythrocyte Zn - Extraversion & I & +0.25 & 84 & 0.023 \\
Erythrocyte Zn - Memory & II & +0.22 & 97 & 0.031 \\
\hline
\end{tabular}

r: correlation index; $n$ : number of subjects; $p$ : significance level 


\section{Discussion}

The work followed Zn levels and psychological features in two apparently healthy pupil groups and the relationship between these aspects. The precarious economic situation of the majority of population in the transition period determines some health problems even in older children and adolescents. If children are further institutionalised, stress and the generally unfavourable climate in the institution influence their psychological development (Macavei, 1989).

As regards the $\mathrm{Zn}$ levels (Table 1), both serum and erythrocyte $\mathrm{Zn}$ levels were significantly higher in group II (the regular school). The cause of this difference may be the stress and the nutrition. The stress alone can cause a rapid fall in plasma $\mathrm{Zn}$ values by reduced food intake and by an increased urinary excretion. Nutrition is very important for $\mathrm{Zn}$ levels from the tissues in general. The nutrition of the children from the orphanage is characterised by a satisfactory, uniform level for all the children. But some of them refuse to eat $\mathrm{Zn}$ rich food like meat or eggs (animal protein) and many of them eat bread in excess and sweets which impair absorption of the metal. The nutrition of the children who live with their families is very variable but generally better, as Zn levels reflect, probably because of socio-economic differences. It seems that they consume more meat, organs (liver, kidney) and eggs and less bread and sweets.

Plasma Zn levels respond very rapidly to a low dietary Zn intake largely because of the limited capacity of the metal to be readily mobilised from other body $\mathrm{Zn}$ deposits. For this reason, plasma $\mathrm{Zn}$ levels in animals and in humans have been observed to fall by up to $50 \%$ within 24 hours of a receiving an inadequate dietary $\mathrm{Zn}$ intake (Dreosti, 1997).

Zn levels determined in this study in apparently healthy children were lower than Zn levels reported by other authors (Laitinen et al, 1989; Van Biervliert et al., 2003; Dabbaghmanesh et al., 2008) in other groups of almost the same age and apparently healthy.

Erythrocyte $\mathrm{Zn}$ reflects the metal status for a longer time period because of their time life of about 120 days (Prasad, 1985). As Table 2 shows, the frequencies of erythrocyte Zn deficit differed significantly between the two groups. This means that, in the orphanage group, comparing with the regular school, there are many more children with erythrocyte $\mathrm{Zn}$ deficit reflecting a serious problem of $\mathrm{Zn}$ nutrition in the case of these children. We talk about the nutrition with red meat, nuts, seeds, cocoa, 
which are foods rich in Zn but also expensive. This nutritional Zn problem in about a quarter of the children from the orphanage group is important because $\mathrm{Zn}$ is mainly an intracellular element and a low erythrocyte concentration that is more stable, emphasizes the depletion of Zn from the body.

Zn levels did not clearly differ between girls and boys (Table 3). If erythrocyte Zn is almost equal in girls and boys, serum $\mathrm{Zn}$ is higher in boys but the difference is significant only in group I. The analysis of weekly menus and food preferences of the children from the orphanage partly explains the low Zn intake by food. In what children from regular school are concerned, it seems that they consume more meet and eggs (Zn rich food) comparing with the children from orphanage.

Regarding intellectual development, we found large gaps referring to the numbers of cases in the two groups for weak attention and very good attention (Figure 1). Also memory differed very much between the two groups in terms of weak, good, and very good memory. The graph for intelligence should capture our attention because the children living in the orphanage do not all have a normal distribution (bell-shaped curve) but an extremely distorted IQ range. Actually, initially, the test for intelligence had a 7 step scale and the distribution of the orphanage children was different, but using this 7 scale for $I Q$, the calculated chi square was not valid (some scoring expected cells $<5$ ).

The differences in the psychological tests between group I and group II can be explained by the different social and emotional conditions experienced by the subjects in the first years of their life when the native psychological potential would have been developed (Macavei, 1989). And, as Engle and Black (2008) show, poverty affects the child's development and educational outcomes beginning in the earliest years of life. The children who live in the orphanages generally come from unstable, low income families, frequently disturbed by alcohol abuse and/or domestic violence. The children born in these families with a psycho-emotional climate, that is adverse to their development and mental health, may be considered to be disadvantaged from birth (Duda, 1996). When they are placed in an orphanage, they have further abnormal emotional conditions which can stress them. On the other hand, the children from the orphanage have a uniform lifestyle (they have a more regular programme of eating, sleeping and physical activities).

Regarding the psychological features and Zn levels, group I (orphanage) showed more relationships than group II (Table 5) probably because the Zn level was lower. 
The correlation index (a more powerful test) emphasized only two correlations of erythrocyte Zn (Table 6).

Our results are in agreements with those of other authors. Two studies among schoolaged children found a beneficial impact of $\mathrm{Zn}$ supplementation on neuropsychological processes, namely reasoning (Black, 2003). Also in children, Zn deficiency has been associated with hyperactivity, sleeping disorders as well as mental retardation (Tuormaa, 1995). A controlled trial of $\mathrm{Zn}$ repletion in stunted Chinese children showed that neuropsychological performance and growth were most improved after treatment with $20 \mathrm{mg}$ Zn with micronutrients (Sandstead et al., 1998). In school-aged children, Thatcher et al. (1984) reported a positive correlation between hair Zn and reading ability. Penland et al. $(1998,2005)$ and Sandstead et al. (1998) used an extensive neuropsychological test battery to measure cognitive and psychomotor function of children in response to repletion with $\mathrm{Zn}$. The consistent finding was that $\mathrm{Zn}$ supplementation resulted in greater improvement than control treatments in performance on tasks assessing visual memory, a word recognition, vigilance and reasoning. Furthermore, it is notable the Kretsch's remark that cognitive changes can occur well ahead of other blood or urine biochemical indicators of decreased $\mathrm{Zn}$. In the test of verbal memory, the men who slowed the most also had the greatest decrease in blood levels of Zn (Kretsch, 2009).

The exact mechanisms of impaired cognitive development are not clear but it appears that $\mathrm{Zn}$ is essential for neurogenesis, neuronal migration, synaptogenesis and its deficiency could interfere with neurotransmission and subsequent neuropsychological behavior (Bhatnagar \& Taneja, 2001). Zn binds with proteins and is considered to be essential for nucleic acid and protein synthesis (Frederickson et al., 2000). That is why Zn deficiency may interfere with these processes and compromise subsequent development. Also, it plays fundamental roles in cell division and maturation, and in the growth and function of many organ systems, including the neurological system. In addition, there is suggestive evidence from animal models (Halas et al., 1977) and psychiatric patients (McLoughin \& Hodge, 1990) that Zn deficiency may affect emotionality and response to stress, factors that may influence infant development. Also, from animal and human findings, it is hypothesized that malnutrition (including zinc malnutrition) impairs neurocognitive functioning by reducing neurons, alternating neurotransmitter functioning and increasing neurotoxicity, and such neurocognitive impairments predispose to externalizing behavior (Liu \& Raine, 2006). Furthermore, $\mathrm{Zn}$ is an antioxidant and this function was first proposed in 1990, based largely upon in vitro evidence that illuminated two distinct mechanisms (Levy \& Bray, 2009): 
- the protection of proteins and enzymes against free radical attack,

- the prevention of free radical formation by other metals, such as iron and copper.

In conclusion, Zn levels, as well as the psychological features, were generally different in the group of children from an orphanage compared to the group from a regular secondary school, perhaps due to the different socio-economical conditions. Our study pointed out many relationships between the serum or erythrocyte Zn level and intellectual development (attention, memory, intelligence) and personality features (neuroticism and extraversion), emphasizing that $\mathrm{Zn}$ is an essential element for normal psychological functioning.

\section{Limitations and perspectives}

This study has some limits that partly are due to the different living conditions of the two groups which forced us to approach them differently (diet registration). Also, the groups are imbalanced regarding the distribution by sexes and the psychological tests were not applied to all children. We suggest that further research is needed, using a more complex model, taking into account at the same time other dietary minerals and other factors (neurological, social, etc.) which may influence together children's psychological development.

\section{References}

Arnold, L.E., \& Di Silvestro R.A. (2005). Zinc in attention-deficit/hyperactivity disorder. Journal of Child and Adolescent Psychopharmacology, 15 (4), 619-627.

Arora, R. B., Subramaniam, T.A.V., Bhatia, B., Khan, S.U., Gaur, S. N., Kheterpal, K., \& Khanna T.(1987). Role of zinc in health and disease. Proceedings of the Second Conference International on Elements in Health and Disease, Karachi, Pakistan, 245-251.

Bhatnagar, S. \& Taneja, S. (2001). Zinc and cognitive development. British Journal of Nutrition, 85, S139- S145.

Black, M.M. (1998). Zinc deficiency and child development. American Journal of Clinical Nutrition, 68 (Suppl 2), 464S-469S.

Black, M.M. (2003). The evidence linking zinc deficiency with children's cognitive and motor functioning. Journal of Nutrition, 133, 1473S-1476S . 
Bogden, J.D., Oleske, J.M., Munves E.M., Lvenhar M.A., Bruening K.S., et al.(1987). Zinc and immunocompetence in the elderly: baseline data on zinc nutriture and immunity in unsupplemented subjects, American Journal of Clinical Nutrition, 46:101-109.

Chen, M.D., Lin, P.Y. \& Sheu, W,H. (1999). Zinc coadministration attenuates melatonin's effect on nitric oxide production in mice. Biological Trace Elements Research, 69(3), 261268.

Choi, D.W. \& Koh, J.Y. (1998). Zinc and brain injury. Annual Review of Neuroscience, 21, 347-375.

Connolly, K.J. \& Kvalsvig, J.D. (1993). Infection, nutrition and cognitive performance in children. Parasitology, 107, S187-S200.

Dabbaghmanesh, M.H., Sadegholvaad, A., Zarei, F. et al. (2008). Zinc status and relation to thyroid hormone profile in Iranian schoolchildren. Journal of Tropical Pediatrics, 54(1), 58-61.

Dreosti, I.E. (1997). Zinc: nutritional aspects, In: Nat Environ Health Monographs, Metal Series No. 2, Zinc, Report of an international meeting, 12-13 September 1996, Adelaide, 14-19.

Duda, R. (1996). Sanatate publica si management, Editura Moldotip, lasi, 108-109.

Engle, P.L. \& Black, M.M. (2008). The effect of poverty on child development and educational outcomes. Annals of the New York Academy of Sciences, 1136, 243-256.

Eysenck, H.J. \& Eysenck, S.B.C. (1975). Manual of the Eysenck Personality Questionnaire. London, Holder \& Stoughton.

Frederickson, C. \& Danscher, G. (1990). Zinc-containing neurons in hippocampus and related CNS structures. Progress in Brain Research, 83: 71-84.

Frederickson, C.J., Suh, S.W., Silva, D. et al. (2000). Importance of zinc in central nervous system: the zinc-containing neuron. Journal of Nutrition, 130, 147S - 153S.

Halas, E.S., Reynolds, G.M. \& Sandstead, H.H. (1977). Intra-uterine nutrition and its effects on aggression. Physiology \& Behavior, 19, 653-661. 
Henkin, R.I., Paten, B.M., Re, P.K., et al. (1975). A syndrome of acute zinc loss: Cerebellar dysfunction, mental changes, anorexia and taste and smell dysfunction. Archives of Neurology, 32, 745-751.

Hodgins, S. \& Ellenbogen, M. (2003), Neuroticism and depression. British Journal of Psychiatry, 182, 79-80.

Kay, A.R. \& Toth, K. (2008) Is zinc a neuromodulator?. Science Signaling, 1 (19), re3.

Kretsch, M.J. (2009). Low zinc leads to faulty memory, Available at: http://findarticles.com/p/articles/mi_m3741/is_10_49/ai_79573967/ Accessed August 6, 2009.

Laitinen, R., Vuori, E., Dahlstrom, S. et al. (1989). Zinc, copper, and growth status in children and adolescents. Pediatric Research, 25(4), 323-326.

Levy, M.A. \& Bray, T.M. (2009). The antioxidant function of dietary zinc and protection against neural disorders, Linus Pauling Institute research report, Available at: http://lpi.oregonstate.edu/ss03/zinc.html Accessed August 6, 2009.

Liu,J. \& Raine, A. (2006). The effect of child malnutrition on externalizing behavior. Current Opinion Pediatrics, 18, 565-570.

Macavei, E. (1989). Familia si casa de copii. Editura Litera, Bucuresti, 117-120.

Martin, N. (2010). Psihodiagnostic 2, Available at:

www.scribd.com/doc/22853646/Psihodiagnoza-2-Suport-de-Curs, Accessed January 25, $2010,8$.

McLoughlin, I.J. \& Hodge, J.S. (1990). Zinc in depressive disorder. Acta Psychiatrica Scandinavica, 82, 451-453.

Neve, J. \& Peretz, A. (1988). Importance nutritionnelle et phisiopahologie du zinc chez I'homme. Journal de Pharmacie de Belgique, 43 (6), 466-477.

Penland, J.G., Lukaski, H. \& Gray, J. (2005). Zinc affects cognition and psychosocial function of middle-school children. Journal of the Federation of American Societies for Experimental Biology. 19(5), A973.

Penland, J.G., Sanstead, H.H., Alcock, N.W. et al. (1998). Zinc and micronutrients affect cognitive and psychomotor function of rural Chinese children. Journal of the Federation of American Societies for Experimental Biology. 12, A649 (abs). 
Pollitt, E. (1994). Poverty and child development: relevance of research in developing countries to the United States. Child Development, 65, 283-295.

Prasad, A.S. (1985). Laboratory diagnosis of zinc deficiency. Journal of American College of Nutrition, 4, 591-598.

Prasad, A.S. (1991). Discovery of human zinc deficiency and studies in an experimental human model. American Journal of Clinical Nutrition, 53, 403-412.

Rajan, K. S., Colburn, R. W., Davis, J. M. (1976). Distribution of metal ions in the subcelular fractions of several rat brain areas. Life Sciences, 18: 423.

Raven, J., Raven, J.C. \& Court, J.H. (2003). Matrici progresive standard. Adaptarea in Romania: coordinator Anca Dobrean, Editura RTS Cluj-Napoca.

Robson, J.R.K. \& Spell, L. (1981). Erythrocyte zinc (letter). American Journal of Clinical Nutrition, 34 (9): 1983.

Roth, H.-P. \& Kirchgessner, M. (1980). Zn-Bindungskapazitat des Serum. Ein Parameter zur Diagnose von marginalem Zn-Mangel. Research in Experimental Medicine (Berl) 177, 213-219.

Sandstead, H.H., \& Penland, J.G. (1997). Essentiality of zinc in human nutrition. In: Nat Environ Health Monographs, Metal Series No. 2, Zinc, Report of an international meeting, 12-13 September 1996, Adelaide, 8-14.

Sandstead, H.H., Penland, J.G., Alcoch, N.W. et al. (1998). Effects of repletion with zinc and other micronutrients on neuropsychologic performance and growth of Chinese children. American Journal of Clinical Nutrition, 68, 470S-475S.

Sandyk, R. (1990). Zinc deficiency in attention-deficit / hyperactivity disorder. International Journal of Neuroscience, 52, 239-241.

Şerbănescu -Grigoroiu, M. (1986). Factor structure and validation of the Junior Eysenck Personality Questionnaire based on a Roumanian sample. International Journal of Psychology, 21:141-151.

Smart, T.G. (2004). Zinc2+ ions: modulators of excitatory and inhibitory synaptic activity. The Neuroscientist, 10(5), 432-442. 
STAS 10542/1-86. Carne si produse din carne. Mineralizarea probelor in vederea determinarii metalelor si arsenului.

Takeda, A. (2000). Movement of zinc and its functional significance in the brain. Brain Research Review, 34(3), 137-148.

Thatcher, R.W., McAlastar, R., Lester, M.L. et al (1984). Comparison among EEG, hair minerals and diet predictions of reading performance in children. Annals of the New York Academy of Sciences, 433: 87-96.

Tuormaa, T.E. (1995). Adverse effects of zinc deficiency: A review from the literature. Journal of Orthomolecular Medicine, 10(3\&4), 149-164.

Van Biervliert, S., Van Biervliert, J-P., Bernard, D. et al. (2003). Serum zinc in healthy Belgian children. Biological Trace Elements Research, 94(1), 33-40.

Vlaicu, B. (2000). Elemente de igiena a copiilor si adolescentilor, Ed. Solness, Timisoara, 102.

Walravens, P.A., van Doorninck, W.J. \& Hambidge K.M. (1978). Metals and mental function. Journal of Pediatrics, 93: 535-541 .

Wang, F.D., Bian, W., Kong, L.W, et al. (2001). Maternal zinc deficiency impairs brain nestin expression in prenatal and postnatal mice. Cell Research, 11, 135-141.

Wauben, I.P., Xing, H.C., \& Wainwright, P.E. (1999). Neonatal dietary zinc deficiency in artificially reared rat pups retards behavioral development and interacts with essential fatty acid deficiency to alter liver and brain fatty acid composition. Journal of Nutrition, 129, 1773-1781.

Yeiser, E.C., Vanlandingham, J.W., \& Levenson, C.W. (2002). Moderate zinc deficiency increases cell death after brain injury in the rat. Nutritional Neuroscience, 5, 345-352.

About the authors

Victoria Papadopol

Ph.D. in pharmacy, Senior researcher, Department of Food Hygiene and Nutrition, Institute of Public Health, lasi, Romania

Area of specialization: trace elements (especially zinc) and magnesium 
Current interests: relationship between trace elements and magnesium and psychological development, nutrition and mental health, relationship between bioelements and nutrition and general health status

Published research papers in refereed Romanian and international journals.

E-mail: vicpapadopol@yahoo.com

Mailing address: Institute of Public Health, 14 Victor Babes Str, 700465, Iasi, Romania

Eugenia Tuchendria

Psychologist, Senior researcher, Department of Food Hygiene and Nutrition, Institute of

Public Health, lasi, Romania

Published research papers in refereed Romanian and international journals.

liana Palamaru

Ph.D. in chemistry, Senior researcher, Department of Food Hygiene and Nutrition, Institute of Public Health, lasi, Romania

Published research papers in refereed Romanian and international journals. 